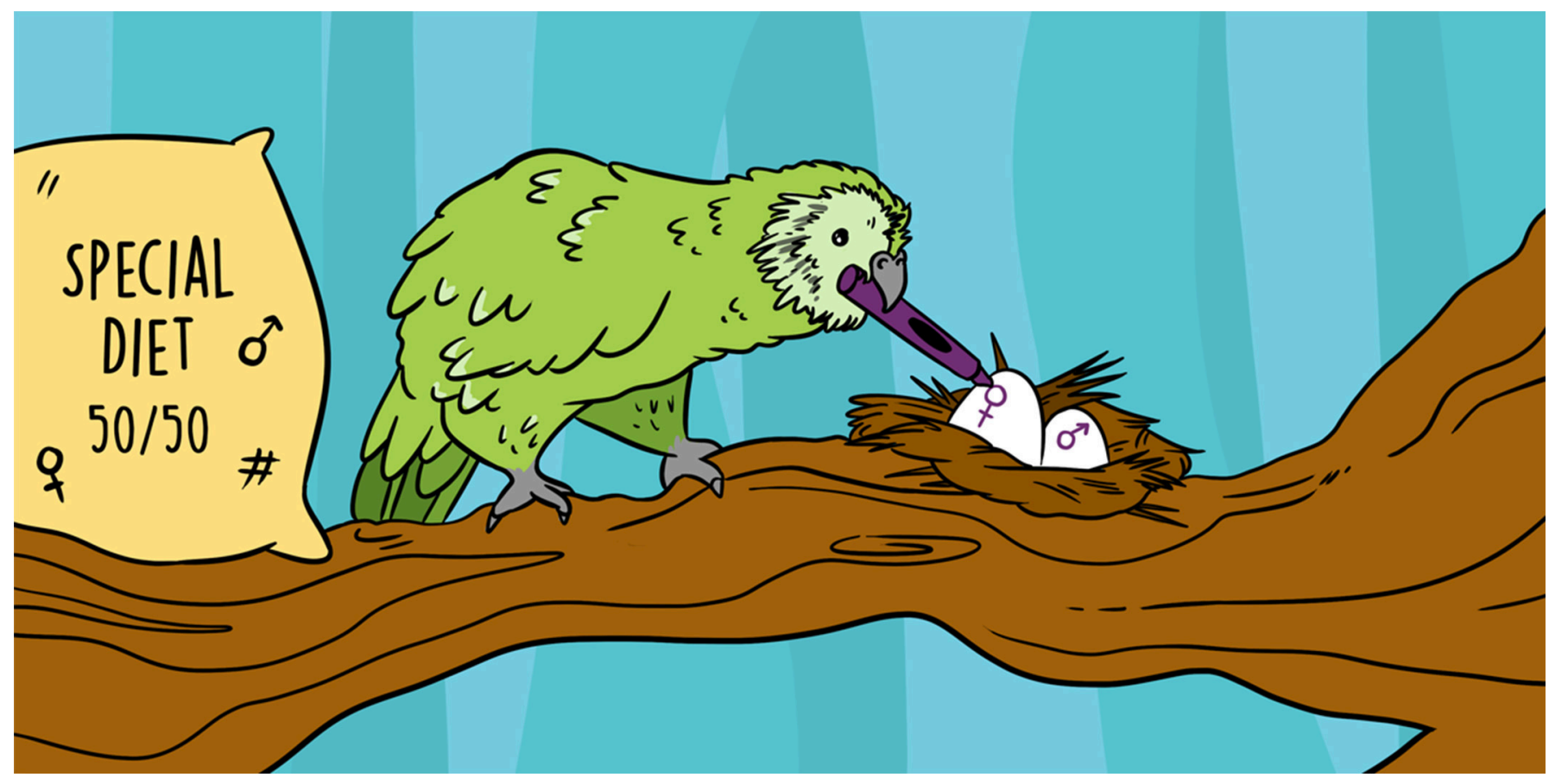

\title{
WHY DOES A MOTHER HAVE SONS OR DAUGHTERS?
}

\section{Nicola Y. Khan *}

Mechanisms of Behavior Lab, School of Psychology and Neuroscience, University of St Andrews, St Andrews, United Kingdom

YOUNG REVIEWERS:

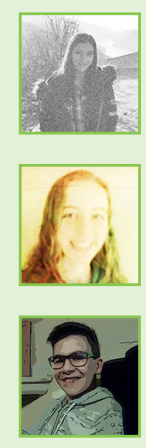

\section{LUANA}

AGE: 13

MADDIE

AGE: 15

VITOR

AGE: 15

We tend to think of the animal reproductive process as being all about males competing for females; males dance, sing, fight, or build a nest, and females dutifully choose the winner. In reality, females invest much more energy into producing offspring than males do, because they are responsible for creating the egg or embryo. Sons and daughters need different amounts of resources and energy from their mothers. Because of this, many female animals can make strategic decisions about whether to have sons or daughters, based on their environment and their own body condition. By "choosing" whether to have sons or daughters, the mother can increase her chances of having grandchildren and thus passing on her own genes. Amazingly, many female animals are able to produce the sex that will serve their interests the most!

Did you know that many different animal species can "choose" whether to have sons or daughters? While a mother does not consciously decide which one to have, her physical condition pushes the probability toward one sex over another. This has been found throughout the animal kingdom, from wasps and spiders to birds and 


\section{SEX RATIO}

the number of females in a population relative to males. For example, if a population of 100 animals had 40 females and 60 males, the sex ratio would be 40:60. You may also see this expressed as 4:6.

\section{HORMONE}

A substance produced in the body that influences the way the body grows or develops and helps the body respond to changes in the environment. mammals. There is even some evidence of such "choice" occurring in humans, but for now, we are going to focus on animals.

Why should we care? If we only think about an individual animal, it does not seem very important to know if a mother gives birth to more sons or daughters. But let us think about this on a community level. Ideally, a community or population would maintain a 50:50 sex ratio (i.e., $50 \%$ females and $50 \%$ males). When a population of animals is small, such as endangered Sumatran tigers, it is very important to know how many males and females there are. If there are not enough females in a population, then there would not be enough mothers, and the population will continue to become smaller. If that happens, that population could die out. So, having a way to control whether a mother has sons or daughters can be good for the whole species. By studying sex ratio biases, scientists could use this information to help increase the number of females in a population. In turn, this could help these populations recover.

\section{MOTHERS PROVIDE ENERGY AND RESOURCES}

We used to believe that parents generate a 50:50 sex ratio, so that they had equal chances of having a son or daughter. However, in 1973, two scientists called Robert Trivers and Dan Willard challenged this theory. They published a paper that said that animals are "selfish" and that they should manipulate the sex of their offspring to maximize their own reproductive success [1]. You can think of sex determination as a game, where the end goal is to make sure that your babies survive to find mates and make babies of their own.

Sons and daughters represent different costs to the mother. Generally, in the animal kingdom, sons are more "expensive" for a mother to produce, as they tend to be larger and more colorful. The mother provides resources (such as glucose, various vitamins, minerals, and hormones) for her young, both when she makes the egg and when she raises her young [2]. However, these resources are allocated differently between sons and daughters, as they have different requirements. Think about peacocks, for example. A peahen (female) is quite small and her feathers are a dull brown. In comparison, a peacock (male) is bigger, very brightly colored, and has long, elaborate tail feathers. These long, brightly colored tail feathers allow a male to attract a mate. It takes a lot of energy to make these feathers, which is why sons are considered "expensive." The energy to grow elaborate feathers comes from the male himself, but his mother gives him extra hormones and other resources to keep him healthy and help ensure that he can grow a long, colorful tail. This initial maternal investment helps her young to survive.

Survival also depends on the animal's environment. A poor environment may not have many resources, such as food or shelter, available. It is more difficult for animals to survive in poor environments, so the 
Figure 1

The potential value of producing a son vs. a daughter. A daughter is almost always going to produce some offspring, even if the environment has few resources. In comparison, a son may be able to produce many more offspring, but only if he is able to outcompete other males for mates. This means he must be big and/or strong, which requires lots of resources.

\section{GENE}

Instructions encoded within the DNA. Genes control the physical or behavioral features of plants and animals, and they are passed on from the parents to the offspring.

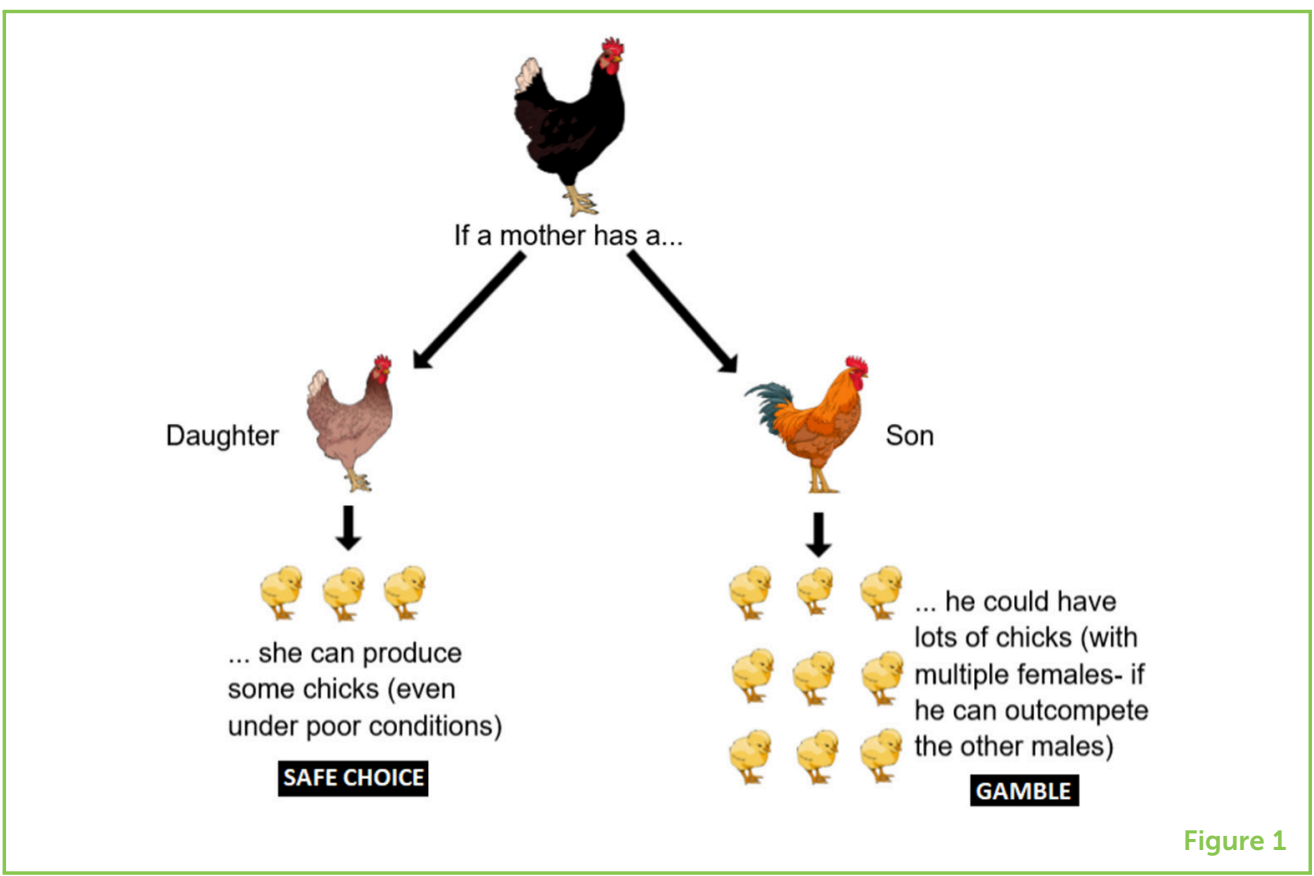

animals must be physically strong and healthy. A good environment has lots of food and water, few predators, and is easier to survive in. If the mother lives in a poor environment, a son may not survive, since he is bigger and needs more food, while a daughter is more likely to survive.

\section{WHY PRODUCE "EXPENSIVE" SONS?}

So, why would a mother choose to put her resources toward having an "expensive" son? Remember, the aim of this game is to have offspring that go on to produce their own offspring. It is in the best interest of mothers to produce the offspring that is most likely to survive and reproduce, thus passing on their genes. A son might be more expensive to produce, but he is able to mate with many females and sire more offspring than a daughter could. So, you can think of having a daughter as being the dependable choice: a daughter will almost always be able to find a mate, but she can only produce a few offspring. However, a son is more of a gamble: a son must compete with other males for a mate; if he wins, he can have lots of offspring with multiple mates. However, if he loses, he would not have any offspring. Because having a son is more of a gamble, a mother who is in good condition and lives in a good environment can afford to take this "high risk/high reward" strategy and produce a big healthy son, who might outcompete other males, mate with lots of females, and generate many grandchildren (see Figure 1).

\section{WHAT FACTORS CAN AFFECT OFFSPRING SEX?}

But exactly how does this work? To be honest, we do not know! There are lots of scientists all over the world that are trying to crack the 


\section{CHROMOSOME}

A rod-shaped structure found in the nucleus of cells. Chromosomes are made of DNA, which contains information about the proteins that need to be made to create the organism. mystery of the mechanism that controls offspring sex. We do know that there are a lot of different factors that affect whether a mother has a son or daughter.

In the nucleus of each cell in an animal's body, the genetic information (DNA) is packaged into rod-shaped structures called chromosomes. Chromosomes exist in matched pairs. One of these pairs of chromosomes is called the "sex chromosomes" and the sex chromosomes control whether offspring are male or female. The sex chromosomes are separated when male and female sex cells (gametes) are formed. The male gametes are the sperm, and the female gametes are the eggs. During fertilization, gametes combine to eventually form an embryo.

In mammals, females have two $X$ sex chromosomes. Males have an $X$ and $a \mathrm{Y}$. Since male mammals donate sperm containing either an $X$ or $Y$ chromosome, but female mammals only have $X$ chromosomes, scientists used to believe that the 50/50 chance of ending up with either a son or daughter was all dependent on the father. However, recent studies have shown that there are variations in the size and shape of sperm that affect which sperm combines with the egg, and therefore whether the resulting offspring is male or female [3]. We also know that a female can influence which chromosome is used, based on her body condition and her environment. So, now we know that both mothers and fathers can influence whether they have sons or daughters.

Sex chromosomes work the opposite way in birds! Female birds have two different sex chromosomes ( $Z$ and $W$ ), while male birds have two Z chromosomes. In birds, the female donates either a Z or a W chromosome to the egg, which determines whether she has sons or daughters. Female birds seem to be able to adjust which sex chromosome the egg receives as a response to the environment [4]. For example, there is a species of parrot living in New Zealand called the kakapo. Kakapo are critically endangered, with only 147 of them remaining in the entire world. Female kakapo must be in good condition to breed, so biologists were feeding them extra food. However, the females then began having only sons! The biologists then performed an experiment [5]: they continued to feed the kakapo, but only small females were allowed to eat as much as they wanted. The kakapo had enough food to stay healthy and breed, but not so much as to gain a lot of weight, which would cause them to have only sons. Then they tallied how many sons and daughters were produced by these birds. Under the new feeding plan, since some females were lighter than others, the chicks had a 50:50 sex ratio!

\section{HORMONES AS SEX ALLOCATION "TRIGGERS"}

It is important to note that animals are not consciously "choosing" one sex over another, but nevertheless, their bodies seem to have adapted 
Figure 2

Changes in the external environment affect the mother's body, such as her hormone levels and her body condition. Stressors are events that cause stress to an animal, for example, a cat chasing a mouse is a stressor for the mouse. The mother's internal environment (her body condition) affects whether she has sons or daughters.

\section{MEDIATOR}

A substance or structure that controls or regulates a specific response in the body. For example, a hormone is considered a mediator, because it controls how the body responds to changes in the environment.

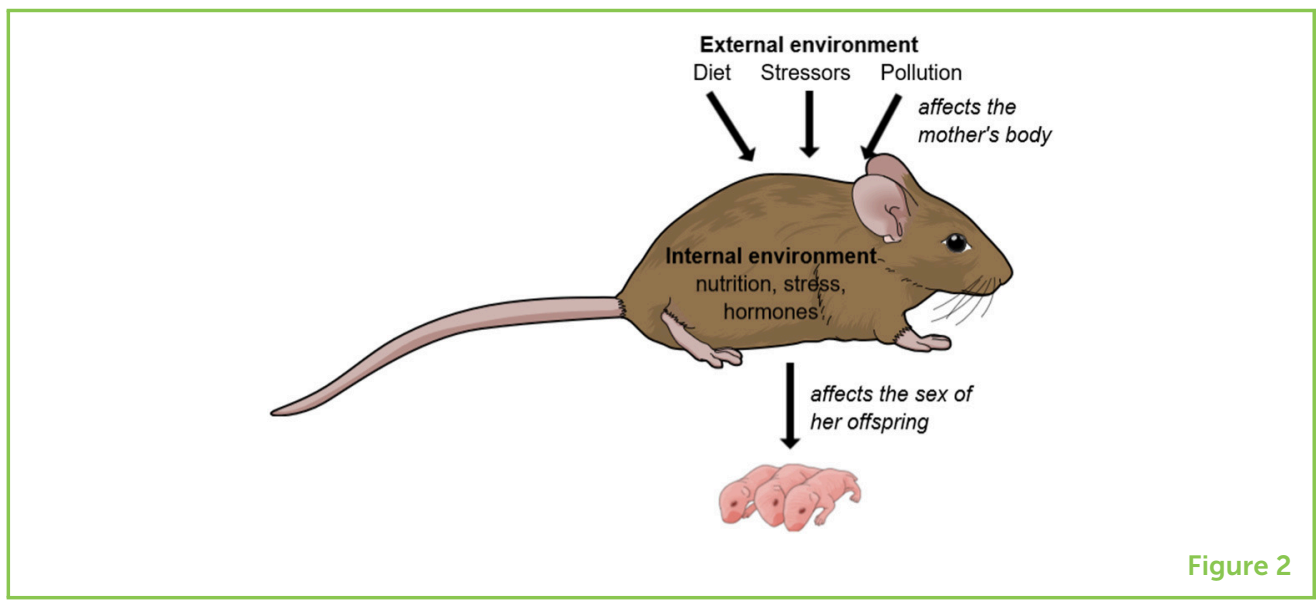

to trigger a "son-making" mode or a "daughter-making" mode, in response to their environments (see Figure 2). Much of this is due to the action of hormones.

Hormones are substances secreted by glands in the body that regulate the functions of many cells and organs. Testosterone (the "male" hormone) and oestrogen (the "female" hormone) can both affect offspring sex ratio. However, other hormones can also affect offspring sex ratio, including stress hormones (called corticosterone in birds and rodents and cortisol in most mammals). For example, if female Japanese quail is given extra corticosterone by scientists, thus increasing their stress level, they produce more daughters than sons [6].

\section{HORMONES SERVE AS THE LINK BETWEEN THE EXTERNAL AND INTERNAL ENVIRONMENTS}

Hormones are mediators between the external environment and the body's condition, or the internal environment. This means that, when something changes in the external environment, hormones make changes in the body so that the animal can cope with the environmental change. We know that if a female lives in a good environment, she will be in much better physical condition than a female that lives in a poor environment. Part of this is simply because a good environment has lots of food available, so the female is getting the nutrition and energy that she needs. A good environment also usually has fewer predators, or less disturbance (such as from humans logging forests), so this female would also be under less stress. Stress affects the body because the body re-directs energy from other body processes, such as digestion or reproduction, and puts that energy toward short-term survival. The stress response gives the body the energy to escape or survive the stressful situation. For example, if a mouse sees a cat, the mouse becomes stressed, due to a surge in stress 
hormones, and the mouse's body uses up extra energy to help it run away and avoid being eaten!

Hormones also interact and affect each other. For example, high levels of the stress hormone corticosterone leads to more daughters, while high levels of testosterone result in more sons [7]. High corticosterone also reduces the production of testosterone, but these hormones naturally vary in concentration throughout the year, so it can be difficult to determine which hormone is driving sex allocation.

\section{SUMMARY}

We know mothers provide sons and daughters with different amounts of resources and energy. As a result, many female animals "choose" whether to have sons or daughters, based on their environment and their own body condition, thereby increasing her chances of having grandchildren and passing on her genes. Right now, scientists all over the world are trying to figure out exactly how these hormones interact and how the entire mechanism of sex determination works. So far, we have discovered many pieces of the puzzle, but it will take years for scientists to fully understand how animals influence the sex of their offspring.

\section{ACKNOWLEDGMENTS}

I would like to thank the three Young Reviewers for their comments and suggestions for improving this article; it is very much appreciated.

\section{REFERENCES}

1. Trivers, R. L., and Willard, D. E. 1973. Natural selection of parental ability to vary the sex ratio of offspring. Science. 179:90-2. Available online at: http://science. sciencemag.org/content/179/4068/90.abstract

2. McGraw, K. J., Adkins-Regan, E., and Parker, R. S. 2005. Maternally derived carotenoid pigments affect offspring survival, sex ratio, and sexual attractiveness in a colorful songbird. Naturwissenschaften. 92:375-80. doi: 10.1007/s00114-005-0003-z

3. Edwards, A. M., Cameron, E. Z., Pereira, J. C., and Ferguson-Smith, M. A. 2016. Paternal sex allocation: how variable is the sperm sex ratio? J. Zool. 299:37-41. doi: $10.1111 /$ jzo.12317

4. Navara, K. J. 2018. "Potential mechanisms of sex ratio adjustment in birds BT," in Choosing Sexes: Mechanisms and Adaptive Patterns of Sex Allocation in Vertebrates, ed K. J. Navara (Cham: Springer International Publishing), 99-121. doi: 10.1007/978-3-319-71271-0_6

5. Clout, M. N., Elliott, G. P., and Robertson, B. C. 2002. Effects of supplementary feeding on the offspring sex ratio of kakapo: a dilemma for the conservation of a polygynous parrot. Biol. Conserv. 107:13-8. doi: 10.1016/S0006-3207(01) 00267-1 
6. Pike, T. W., and Petrie, M. 2006. Experimental evidence that corticosterone affects offspring sex ratios in quail. Proc. R. Soc. B Biol. Sci. 273:1093-8. doi: 10.1098/rspb.2005.3422

7. Navara, K. J. 2018. "Hormones rule the roost: hormonal influences on sex ratio adjustment in birds and mammals BT," in Choosing Sexes: Mechanisms and Adaptive Patterns of Sex Allocation in Vertebrates, ed K. J. Navara (Cham: Springer International Publishing), 123-154. doi: 10.1007/978-3-31971271-0_7

SUBMITTED: 25 September 2018; ACCEPTED: 26 April 2019; PUBLISHED ONLINE: 10 May 2019.

EDITED BY: Pedro Morais, University of California, Berkeley, United States

CITATION: Khan NY (2019) Why Does a Mother Have Sons or Daughters? Front. Young Minds 7:66. doi: 10.3389/frym.2019.00066

CONFLICT OF INTEREST STATEMENT: The author declares that the research was conducted in the absence of any commercial or financial relationships that could be construed as a potential conflict of interest.

COPYRIGHT (C) 2019 Khan. This is an open-access article distributed under the terms of the Creative Commons Attribution License (CC BY). The use, distribution or reproduction in other forums is permitted, provided the original author(s) and the copyright owner(s) are credited and that the original publication in this journal is cited, in accordance with accepted academic practice. No use, distribution or reproduction is permitted which does not comply with these terms.

\section{YOUNG REVIEWERS}

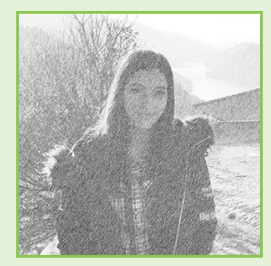

\section{LUANA, AGE: 13}

I like to roller skating, ride a bike, watch movies, and hang out with my friends.

\section{MADDIE, AGE: 15}

In my free time, I love playing flute, printmaking, and participating in Academic Decathlon. I am interested in how entrepreneurship and sustainability can work together. Someday, I hope to have a career which incorporates both fields.

\section{VITOR, AGE: 15}

I am a 15 years old Portuguese boy. I like nature in general. I wish to be a psychologist because I like to talk with people about their problems and help them. I love music and one of my hobbies is learning and playing music. 


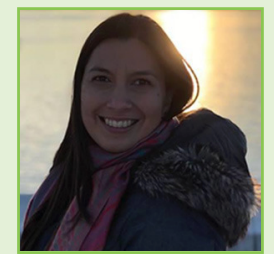

\section{AUTHOR}

\section{NICOLA Y. KHAN}

I grew up in the Fiji Islands and always loved watching and learning about animals. As a teenager, I read about how hormones were being excreted into waterways and the ocean and were affecting marine life. Understanding how changes in the environment and hormones work together became my primary research interest, and I now study how stress affects animals. In my free time, I enjoy traveling, reading, and spending time with my dog, friends, and family. *niki.y.khanagmail.com 